Journal of Mathematics and Informatics

Vol. 11, 2017, 13-15

ISSN: 2349-0632 (P), 2349-0640 (online)

Published 11 December 2017

www. researchmathsci.org

DOI: http://dx.doi.org/10.22457/jmi.v1 la2

Journal of

Mathematics and

Informatics

\title{
Hexagonal Numbers and Pythagorean Triangles
}

\author{
P.Jayakumar $^{1}$ and G.Shankarakalidoss ${ }^{2}$ \\ ${ }^{1}$ Department of Mathematics, A.V.V.M. Sri Pushpam College (Autonomous) \\ Poondi, Thanjavur-613 503 \\ Email: pjkumar58@gmail.com \\ ${ }^{2}$ Department of Mathematics, Kings College of Engineering \\ Punalkulam, Pudukkottai (Dt) -613 303 \\ Email: shankarakalidoss@yahoo.com
}

Received 1 November 2017; accepted 4 December 2017

\begin{abstract}
The oblong numbers were first studied by Pythagorean. These numbers are studied in terms of special Pythagorean Triangles. The perimeters of such triangles are obtained as a double of hexagonal numbers. Existence of Pythagorean triangles with two consecutive sides and their perimeters as a double of hexagonal numbers is also investigated.
\end{abstract}

Key words: Hexagonal numbers, Pythagorean Triangles.

AMS Mathematics Subject Classification (2010): 11D09

\section{Introduction}

In 2005, Gopalan and Devibala [2] studied Special Pythagorean triangle. In 2008, Gopalan and Janaki [3] investigated Pythagorean triangles with perimeter as a pentagonal number. In 2010, Gopalan and Vijayalakshmi [1] observed Special Pythagorean triangles generated through the integral solutions of the equation $y^{2}=\left(k^{2}+1\right) x^{2}+1$. After that Mita [4] investigated about oblong numbers and Pythagorean triangles. He found that perimeter of the Pythagorean triangles are as oblong numbers.

Inspired by all the aforementioned results, this paper aim to study the perimeter of the Pythagorean triangles are as a double of hexagonal numbers.

\section{Method of analysis}

The primitive solutions of the Pythagorean Equation,

$\mathrm{X}^{2}+\mathrm{Y}^{2}=\mathrm{Z}^{2}$, is given by [5]

$\mathrm{X}=\mathrm{m}^{2}-\mathrm{n}^{2}, \mathrm{Y}=2 \mathrm{mn}, \mathrm{Z}=\mathrm{m}^{2}+\mathrm{n}^{2}$

for some integers $\mathrm{m}, \mathrm{n}$ of opposite parity such that $\mathrm{m}>\mathrm{n}>0$ and $(\mathrm{m}, \mathrm{n})=1$

\section{Perimeter is a double of hexagonal number}

Definition 3.1. A natural number ' $h$ ' is called a double of hexagonal numbers if it can be written in the form $2 \mathrm{u}(2 \mathrm{u}-1), \mathrm{u} \varepsilon \mathrm{N}$. 
P.Jayakumar and G.Shankarakalidoss

If the perimeter of the Pythagorean triangles $(\mathrm{X}, \mathrm{Y}, \mathrm{Z})$ are as a double of hexagonal numbers ' $\mathrm{h}$ ', then

$\mathrm{X}+\mathrm{Y}+\mathrm{Z}=2 \mathrm{u}(2 \mathrm{u}-1)=\mathrm{h}$

From the equations (2) \& (3)

$2 \mathrm{~m}^{2}+2 \mathrm{mn}=2 \mathrm{u}(2 \mathrm{u}-1), \mathrm{u} \varepsilon \mathrm{N}$.

$\mathrm{m}(\mathrm{m}+\mathrm{n})=\mathrm{u}(2 \mathrm{u}-1)$

4. Hypotenuse and one leg are consecutive

In such cases, $\mathrm{m}=\mathrm{n}+1$

This gives equation (4) as

$(\mathrm{n}+1)(2 \mathrm{n}+1)=\mathrm{u}(2 \mathrm{u}-1)$

Take $\mathrm{u}=\mathrm{n}+1$

Equations (2), (5) and (6) give solution of equations (1) in correspondence with equations

(3) and (4) i.e.,

$\mathrm{X}=2 \mathrm{n}+1$

$\mathrm{Y}=2 \mathrm{n}(\mathrm{n}+1)$

$\mathrm{Z}=2 \mathrm{n}(\mathrm{n}+1)+1$

First ten such special Pythagorean triangles (X, Y, Z) are given in the Table 4.1 below:

\begin{tabular}{|c|c|c|c|c|c|c|c|}
\hline S. No. & $\mathbf{n}$ & $\mathbf{u}$ & $\mathbf{h}$ & $\mathbf{X}$ & $\mathbf{Y}$ & $\mathbf{Z}$ & $\mathbf{X}+\mathbf{Y}+\mathbf{Z}=\mathbf{2 u}(\mathbf{2 u}-\mathbf{1})$ \\
\hline 1 & 1 & 2 & 12 & 3 & 4 & 5 & $12=2.2 .3$ \\
\hline 2 & 2 & 3 & 30 & 5 & 12 & 13 & $30=2.3 .5$ \\
\hline 3 & 3 & 4 & 56 & 7 & 24 & 25 & $56=2.4 .7$ \\
\hline 4 & 4 & 5 & 90 & 9 & 40 & 41 & $90=2.5 .9$ \\
\hline 5 & 5 & 6 & 132 & 11 & 60 & 61 & $132=2.6 .11$ \\
\hline 6 & 6 & 7 & 182 & 13 & 84 & 85 & $182=2.7 .13$ \\
\hline 7 & 7 & 8 & 240 & 15 & 112 & 113 & $240=2.8 .15$ \\
\hline 8 & 8 & 9 & 306 & 17 & 144 & 145 & $306=2.9 .17$ \\
\hline 9 & 9 & 10 & 380 & 19 & 180 & 181 & $380=2.10 .19$ \\
\hline 10 & 10 & 11 & 462 & 21 & 220 & 221 & $462=2.11 .21$ \\
\hline
\end{tabular}

Table 4.1: Special Pythagorean Triangles and Verification of

$$
\mathrm{X}+\mathrm{Y}+\mathrm{Z}=2 \mathrm{u}(2 \mathrm{u}-1) \text {. }
$$

5. Remarkable observations

1. $(2 X-Y+Z)^{2}=X^{2}+2(X+Y+Z)+2(X+Z)$

2. $(3 \mathrm{X}+\mathrm{Z}-\mathrm{Y})^{2}=3[3(\mathrm{Y}+\mathrm{Z})+2 \mathrm{X}]+\mathrm{Z}-\mathrm{Y}$

\section{REFERENCES}

1. M.A.Gopalan and P.Vijalakshmi, Special Pythagorean triangles generated through the integral solutions of the equation $\mathrm{y}^{2}=\left(\mathrm{k}^{2}+1\right) \mathrm{x}^{2}+1$, Antarctica J. Math., 7(5) (2010) 503-507.

2. M.A.Gopalan and S.Devibala, Special Pythagorean triangle, Acta Ciencia Indica, 31(1) M2005) 39-40.

3. M.A.Gopalan and G.Janaki, Pythagorean triangles with perimeter as a pentagonal number, Antarctica J. Math., 5(2) (2008) 15-18. 
Hexagonal Numbers and Pythagorean Triangles

4. D.Mita, Oblong numbers and Pythagorean triangles, Americal Jr. of Mathematics and Sciences, 1(1) (2012) 75-78.

5. I.Niven and Herbert S. Zuckerman, An Introduction to the Theory of Numbers, Wiley Eastern Limited, New Delhi, 1976. 